\title{
MAPEAMENTO DO CONTEÚDO DE CLOROFILA FOLIAR A PARTIR DE SISTEMA DE INFORMAÇÕES GEOGRÁFICAS EM CRATO/CE
}

\section{Daliane da Silva Batista ${ }^{1}$; Alex Costa de Souza ${ }^{2}$; Cícero Aparecido Ferreira Araújo ${ }^{3}$; Gilberto Saraiva Tavares Filho ${ }^{4}$; Cicero Cordeiro Pinheiro ${ }^{5}$; Jucivânia Cordeiro Pinheiro ${ }^{6}$; Mateus Fernandes Barbosa das Neves ${ }^{7}$; Janailton Coutinho ${ }^{8}$}

\begin{abstract}
${ }^{1}$ Graduanda em Agronomia, Universidade Federal do Cariri (UFCA), Crato, Ceará, ${ }^{2}$ Graduando em Agronomia, Universidade Federal do Cariri (UFCA), Crato, Ceará, ${ }^{3}$ Graduando em Agronomia, Universidade Federal do Cariri (UFCA), Crato, Ceará, ${ }^{4}$ Mestrando em Engenharia Agrícola, Universidade Federal do Vale do São Francisco (UNIVASF), Juazeiro da Bahia, Bahia, ${ }^{5}$ Graduando em Agronomia, Universidade Federal do Cariri (UFCA), Crato, Ceará, ${ }^{6}$ Mestranda em Fitotecnia, Universidade Federal Rural do Semi-Árido (UFERSA), Mossoró, Rio Grande do Norte, ${ }^{7}$ Graduando em Agronomia, Universidade Federal do Cariri (UFCA), Crato, Ceará, ${ }^{8}$ Doutorado em Educação Brasileira, Universidade Federal do Ceará, Fortaleza, Ceará.
\end{abstract}

DOI: $10.47094 / I C O N N E C A .2021 / 19$

\section{RESUMO}

O Sistema de Informações Geográficas (SIG) é um conjunto de sistemas e técnicas computacionais que opera sobre bases de dados georreferenciados para transformá-los em informação relevante que sirva para a tomada de decisão. Destaca-se no mapeamento da Clorofila Verde, essencial nas Ciências Agrárias. O Índice de Clorofila Verde (IGC) é utilizado para quantificar a quantidade total de clorofila nas plantas a partir da banda do verde e Infravermelho próximos, no qual são sensíveis a ligeiras variações na quantidade de clorofila e são consistentes para a maioria dos tipos de plantas. Nesse sentido, o presente trabalho objetiva analisar o ICG no município de Crato, com a finalidade de estimar o teor de clorofila em folhas a partir de Imagens do satélite Landsat-8. Os resultados demonstraram que os maiores valores de IGC foram mais elevados nas áreas circunvizinhas do centro do município, caracterizando uma expansão da cidade, diminuindo as áreas arborizadas.

PALAVRAS-CHAVES: Sensoriamento Remoto. Análise Espacial. Saúde da Vegetação.

ÁREA TEMÁTICA: Geoprocessamento e tecnologia digital nas ciências agrárias.

\section{INTRODUÇÃO}

A mudança tecnológica na agricultura nas últimas décadas, especialmente, após os avanços tecnológicos de posicionamento georreferenciado, como o GPS, do sensoriamento remoto e dos softwares de Sistema de Informações Geográficas (SIG), tem sido o foco da pesquisa na área, por desempenhar uma função de decisão no atendimento às demandas futuras de produtos agrícolas 
(HERTEL; BALDOS; MENSBRUGGHE, 2016).

O SIG pode ser usado para quantificar a área e o conteúdo de clorofila e pode ser usado em pesquisas fisiológicas e agronômicas para avaliar o desenvolvimento e o crescimento das plantas. Essas variáveis são significativas no estudo do desempenho vegetativo das espécies e na resposta da planta a técnicas de manejo destinadas a aumentar a fotossíntese e aumentar o potencial de rendimento (AMARANTE et al., 2009).

Destaca-se o Índice de Clorofila Verde (ICG), utilizado para estimar o conteúdo de clorofila foliar em várias espécies de plantas. Sendo assim, é objeto de estudo do presente trabalho analisar o ICG no município de Crato, com a finalidade de estimar o teor de clorofila em folhas.

\section{METODOLOGIA}

O presente trabalho foi desenvolvido no município do Crato-CE, situado na Região Metropolitana do Cariri - RMC. A sede do município do Crato apresenta como coordenadas geográficas $7^{\circ} 14^{\prime} 03$ ” de Latitude (S) e 39²4'34” de Longitude (W).

A primeira etapa desse trabalho foi a obtenção das imagens orbitais, especialmente as bandas Operational Land Imager: OLI2, OL3, OLI4, OLI5, OLI6, OLI7 do satélite Landsat-8, imagens obtidas pelo Serviço Geológico dos Estados Unidos - United States Geological Survey (USGS), órbita 217 e ponto 65. A imagem escolhida para esse estudo é de 03/08/2019. As imagens do satélite foram reprojetadas para o Hemisfério Sul e foram cortadas a partir da delimitação do município de Crato a partir dos dados vetoriais do IBGE. Posteriormente, foi realizado a aritmética de bandas, utilizando o software Qgis, utilizando a Equação, no qual Green é a banda do verde e NIR a banda do Infravermelho próximo.

\section{RESULTADOS E DISCUSSÕES}

O Índice de Clorofila Verde é utilizado para quantificar a quantidade total de clorofila nas plantas a partir da banda do verde e Infravermelho próximos, no qual são sensíveis a ligeiras variações na quantidade de clorofila e são consistentes para a maioria dos tipos de plantas. A partir do mapeamento no software Qgis, a partir das imagens do satélite Landsat-8 (Figura 1), a partir da cor falsa, onde é aplicada com finalidade de visualizar os dados para uma análise eficiente.

A paleta de cores varia do vermelho (terra nua e urbanização) ao verde (plantas saudáveis). A cor verde indica áreas onde a vegetação se desenvolve melhor e a quantidade de clorofila é alta, já o amarelo e verde pálido são os locais com vegetação não bem formadas ou locais desmatados, já a cor laranja e vermelho são os locais com pouca quantidade de clorofila, podendo ser locais de solo exposto, locais urbanizados ou até vegetação que não se encontra saudável. 
Percebe-se na Figura 1 que os maiores valores de GCI foram mais elevados nas áreas circunvizinhas do centro do município, caracterizando uma expansão da cidade, diminuindo as áreas arborizadas, como exemplo, nas áreas localizados na Floresta Nacional do Araripe, uma Unidade de Conservação situada na Chapada do Araripe administrada pelo ICMBio. No centro do município, os baixos valores estão associados a presença de grandes áreas impermeabilizadas, já os valores mais altos foram localizados na Floresta Nacional do Araripe.

Figura 1: Mapeamento do índice de Clorofila Verde para o município de Crato - CE

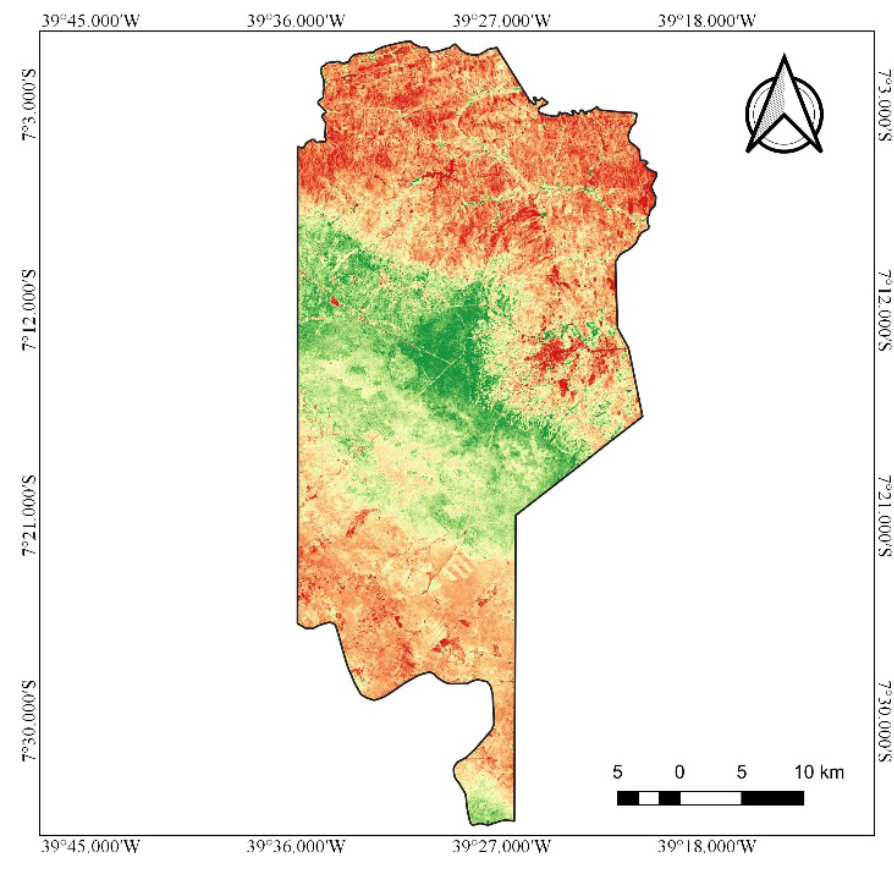

Fonte: Autores (2021). Elaborado no software Qgis 4.3.
Índice de Clorofila Verde (GCI) do município de

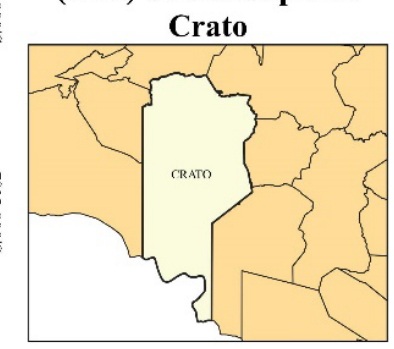

$$
\text { Legenda }
$$

$\square$ Municipio de Crato

$\square$ Limites municipais

$\mathrm{GCI}$

\begin{tabular}{r}
$\square .48$ \\
$\square 1.62$ \\
\hline \\
1.75
\end{tabular}

$\square 1.75$

$\square 2.03$

$\square 2.16$

Sistema de Coordenadas Geográficas WGS

84 / Zone $24 \mathrm{~S}$

Fonte de dados: IBGE (2021) e USGS (2021)

Os baixos valores são devido a reflectância vegetal alterada pelo processo de alteração da área fotossinteticamente ativa da planta, ocasionada pelo processo de sucessão ou supressão desta.

\section{CONCLUSÃO}

A partir da análise dos resultados, verificou-se apenas alguns fragmentos com alto vigor vegetativo no município de Crato, como exemplo os valores mais altos localizados na Floresta Nacional do Araripe, uma Unidade de Conservação situada na Chapada do Araripe. Já o restante do município apresentou baixo índice, visto alto processo de urbanização nas últimas décadas. 


\section{PRINCIPAIS REFERÊNCIAS}

AMARANTE, Cassandro Vidal Talamini do et al. Quantificação da área e do teor de clorofilas em folhas de plantas jovens de videira'Cabernet Sauvignon'mediante métodos não destrutivos. Revista Brasileira de Fruticultura, v. 31, n. 3, p. 680-686, 2009.

BERNARDI, Alberto C. de Campos et al. Ferramentas de agricultura de precisão como auxílio ao manejo da fertilidade do solo. Cadernos de Ciência \& Tecnologia, v. 32, n. 1/2, p. 211-227, 2017.

HERTEL, Thomas W.; BALDOS, Uris LantzC.; VAN DER MENSBRUGGHE, Dominique. Predicting long-term food demand, cropland use, and prices. Annual Review of Resource Economics, v. 8, p. 417-441, 2016. 